\title{
La prefijación como estrategia de la persuasión publicitaria: de la neología a la argumentación
}

\author{
Javier VELLÓN LAHOZ ${ }^{1}$ \\ Universitat Jaume I
}

\begin{abstract}
RESUMEN:
El artículo trata sobre el uso de la prefijación en los textos publicitarios. A partir del análisis de los prefijos más característicos en la publicidad (re-, anti-, des-, pro- y los cuantitativos de grado), se observa su función en el proceso argumentativo de los anuncios, especialmente los dedicados a productos de belleza. En primer lugar, como reclamo visual al situarse como foco de la estrategia perceptiva que condiciona la composición de la escena textual; a continuación, como mecanismo cognitivo a partir de los valores aspectuales del morfema derivativo; finalmente, como eje de la macroproposición temática relacionado con los tópicos más habituales de la persuasión publicitaria capaz de actuar sobre el mapa cultural del destinatario, en su doble condición, social y personal.
\end{abstract}

PALABRAS CLAVE: argumentación publicitaria; lenguaje publicitario; tópicos publicitarios; estrategias de persuasión; imaginario colectivo.

TITLE: Prefixing as advertising persuasion strategy: from the neology to argumentation

\begin{abstract}
:
The article is about the use of prefixation in advertising texts. From the analysis of characteristic prefixes in advertising (re-, anti-, dis-, pro- and the grade quantitatives), we see its role in the argumentative process of the ads, especially those dedicated to beauty products . First, as a visual lure to position itself as a focus of perceptual strategy that determines the composition of the textual scene ; then, as a cognitive mechanism from aspectual values of derivational morpheme; and finally, as the axis of the theme macro-proposition relationed to the most common topics of advertising persuasion that can act on the cultural map of the receiver, in his dual capacity, social and personal.
\end{abstract}

KEY WORDS: argumentation advertising; language of advertising; advertising topics: strategies of persuasion; collective imagination.

\section{Introducción}

El texto publicitario, en su dimensión verbal, posee una finalidad persuasiva en tres modalidades -racional, emotiva e inconsciente, como indica C. Lomas ${ }^{2}-$, y persigue explícitamente un efecto perlocucionario que se traduce en la transformación del recep-

1 Profesor del Área de Lengua Española del Departamento de Filología y Culturas Europeas de la Universitat Jaume I. Imparte docencia en los grados de Periodismo y de Publicidad. E-mail: ve1lon@fil.uji.es. El artículo se inscribe en el proyecto 'El discurso divulgativo en catalán y en español: géneros, estilos y estrategias argumentativas en la gestión social del conocimiento' (PI-IB2011-53).

2 LOMAS, C. (1996): El espectáculo del deseo. Usos y formas de la persuasión publicitaria, Barcelona, Octaedro, 46 
tor del mensaje en consumidor. Para ello pone su acento en el efecto comunicativo sobre el destinatario y sobre el impacto de la acción semiótica, de manera que se genera un proceso circular en el que los efectos retroactúan sobre las causas, intensificando así la interacción texto/receptor.

Esta singularidad argumentativa, junto al carácter particular que le aporta su naturaleza «plurisígnica», en terminología de Romero Gualda ${ }^{3}$-las interferencias intersemiológicas de las que hablan Adam y Bonhomme ${ }^{4}$ - determinada por la heterogeneidad de códigos que actúan en sincretismo, comportan notables implicaciones sobre los mecanismos de la textualización y sobre los diferentes procedimientos discursivos:

- En primer lugar, el texto publicitario desarrolla un esquema de actuación sobre un destinatario con el fin de convencerlo acerca de las cualidades de un producto, no desde una metodología especulativo-deliberativa, sino a partir de mensajes con fuerte impacto emocional que, a su vez, en un estadio posterior, se consolidan como esquemas cognitivos en la memoria a largo plazo.

- Además, el texto publicitario actúa sobre la esfera cognitiva de las creencias, los valores personales y sociales, lo que constituye otro de sus objetivos, a sumar a los más explícitos dirigidos al dominio perceptivo. En este sentido, la vertebración semántica de la argumentación actualiza los diferentes tópicos que garantizan la coherencia temática del mensaje, así como la efectividad de un texto inicialmente concebido para captar la atención sensorial del interlocutor.

- Finalmente, el texto, entendido como «una puesta en escena», en la terminología de la lingüística perceptiva, proyecta la conversión semiótica de la letra con la función de orientar el acto de recepción hacia la entidad visual del texto, rompiendo así con la linealidad y discursividad del lenguaje verbal. De este modo, el proceso de focalización, clave para valorar la estrategia intencional y comunicativa del texto (así lo plantea Gutiérrez Ordóñez ${ }^{5}$ para quien el foco es «un punto en el que confluyen los vectores intencionales del emisor»), pasa a depender, en primer lugar, ya no sólo de parámetros propios del semantismo lingüístico, sino también de caracteres organizativos del signo visual, tales como la dimensión (aspectos tipográfico, tipo de letra, color, tamaño), la posición en el espacio perceptivo (centralidad/marginalidad, alto/bajo, etc.) y la orientación, siguiendo el principio de las jerarquías visuales.

3 ROMERO, $\mathrm{M}^{\mathrm{a}} \mathrm{V}$. (2002): «Texto e imagen en el texto publicitario», en ROMERO GUALDA, $\mathrm{M}^{\mathrm{a}} \mathrm{V}$. (coord.): Lenguaje publicitario, Barcelona, Ariel, 83-87, p. 84.

4 AdAM, J. y Bonhomme, M. (2000): La argumentación publicitaria. Retórica del elogio y de la persuasión, Madrid, Cátedra. 86-91. 34.

GUTIÉRREZ ORDÓÑEZ, S. (2000): Temas, remas, focos, tópicos y comentarios, Madrid, Arco-Libros, 
El análisis de la prefijación refleja estas tres vertientes del texto publicitario: la focalización del proceso argumentativo en la semantización de la grafía y su marco de realización en el escenario persuasivo, convertida en signo icónico que articula el itinerario de lectura hasta convertirse en una «composition essentiellemeny visuelle» en palabras de Krüger ${ }^{6}$; la creatividad neológica dirigida a la persuasión afectiva a través de la motivación semántica de las unidades léxicas y de sus componentes morfológicos; finalmente, la transmisión de valores a partir del efecto connotativo de los formantes lexicogenéricos, que apelan a pulsiones íntimas del imaginario colectivo hasta constituir un paisaje comunicativo, ya que, como indica Codeluppi ${ }^{7}$ "el consumidor busca hoy en día un conjunto de significados simbólicos [...] más que la satisfacción de tipo funcional».

\section{El prefijo como signo visual en el texto publicitario}

En el dominio publicitario, el prefijo puede llegar a adquirir autonomía formal respecto al conjunto de la palabra, constituyendo un complejo gráfico-eufónico-icónico mediante el que se organiza el proceso argumentativo del texto

La primacía perceptivo-comunicativa de la prefijación, así como su identidad fónico-gráfica, da lugar a estrategias dirigidas a preservar su sobresignificación, entre las que pueden destacarse las siguientes: Mecanismos encaminados a otorgar preeminencia semántico-formal al afijo con el fin de potenciar su función catalizadora del proceso persuasivo del enunciado. Se trata de un modelo de conversión del signo lingüístico en formema, insistiendo en el valor perceptual del formante lexicogenérico como marco de su virtualidad connotativa, cumpliendo así el principio del lenguaje publicitario expuesto por Robles ${ }^{8}:$ «explotar al máximo el rendimiento de los elementos lingüísticos utilizados en la configuración del mensaje».

Es frecuente la aparición de prefijos indepedientes de la base léxica, marcando la no cohesión gráfica mediante guiones, de manera que tanto en la linealidad perceptiva del significante, como en su autonomía morfosemántica, cobran relevancia en la organización de la textualidad argumentativa.

En este caso, es patente el uso de prefijos con una gran productividad en los procesos derivativos y una notable accesibilidad como formantes analizables por los hablantes. Así sucede con los cuantitativos («multi-hidratante», «ultra-confortable») y, sobre todo, con los de valor aspectual de oposición («anti-caída, anti-edad, anti-fatiga, descafeinado»).

La prevalencia de la función persuasiva, incluso de la libertad creativa en las disposiciones formales de un discurso determinado por su capacidad performativa, sobre

6 KRÜGER, R. (1990): «L'écriture et le conquête de l'espace plastique: comment le texte es devenu image», en Montandon, A. (ed.), Signe/texte/image, Lyon, Césura Lyon Edition, 13-61, 33.

CodelupPI, V. (2007): «El papel social de la publicidad», Pensar la Publicidad, I, 1, 144-155.

8 RoBles, S. (2004): Realce y apelación en el lenguaje de la publicidad, Madrid, Arco-Libros, 13. 
la norma culta de escritura, refleja una de las singularidades del lenguaje publicitario, como puede observarse en los ejemplos en los que dicha estrategia afecta a unidades léxicas-«des-cansa, des-preocúpate»-de uso cotidiano por parte del destinatario.

La dislocación forzada de los componentes léxicos, además de contribuir a la identificación neológica de la palabra -como sucede en el lenguaje periodístico según indica Guerrero ${ }^{9}-$, manifiesta el deseo de acomodar la expresión a un modelo de verbalidad que, en su búsqueda del potencial argumentativo de los signos, no duda en romper con las constricciones de una norma basada en la exclusiva viabilidad informativa del mensaje.

La constatación de esta tendencia caracterizadora del lenguaje publicitario se observa en la figura 1, en la que la segmentación de los formantes de la palabra «rebajas» reconstruye textualmente un término que, por su uso, se ha convertido en una entidad que ha lexicalizado su origen derivativo en la conciencia del hablante. La dimensión perceptiva se sobrepone a la identidad léxica del vocablo.

Fig. 1

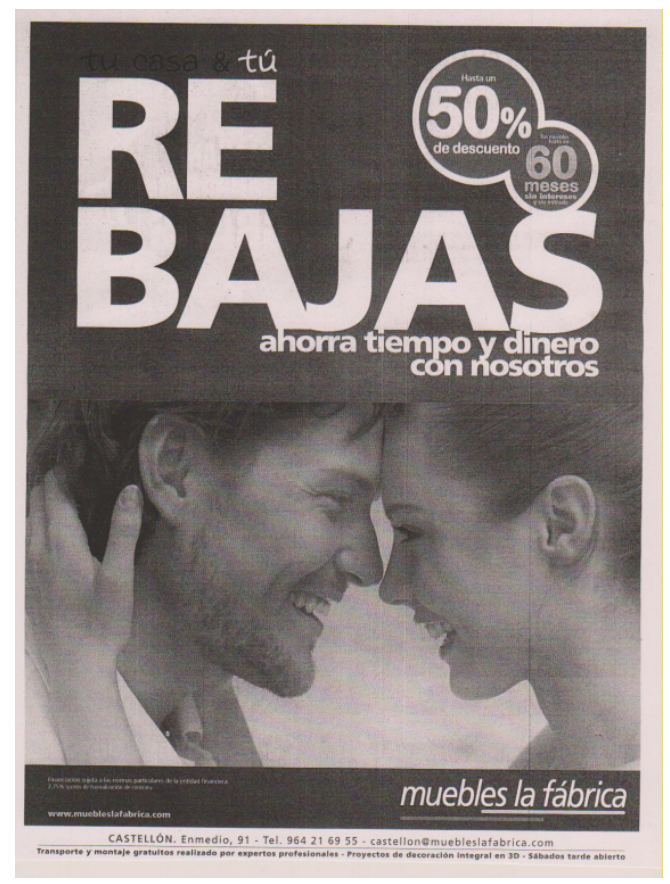

En segundo lugar, la remotivación icónica de las grafías del prefijo se desarrolla por la inclusión del mensaje verbal en el conjunto de la imagen, con lo que se logra adaptar la lectura a la dimensión espacializada de la forma. El resultado es un estadio

9 Guerrero, S. (2007): La creatividad en el lenguaje perodístico, Madrid, Cátedra, 116 y ss. 
mayor de integración entre códigos y un salto cualitativo en la ruptura con la dinámica de recepción del signo lingüístico desde el orden oral a la dimensión visual.

En el caso de la figura 2, la señalización perceptiva de los prefijos (re-) mediante las imágenes no sólo refuerza su autonomía respecto a la base, sino que apunta al sentido referencial sobre el que se formula la motivación semántica, que va desde el afijo a la palabra.

Fig. 2

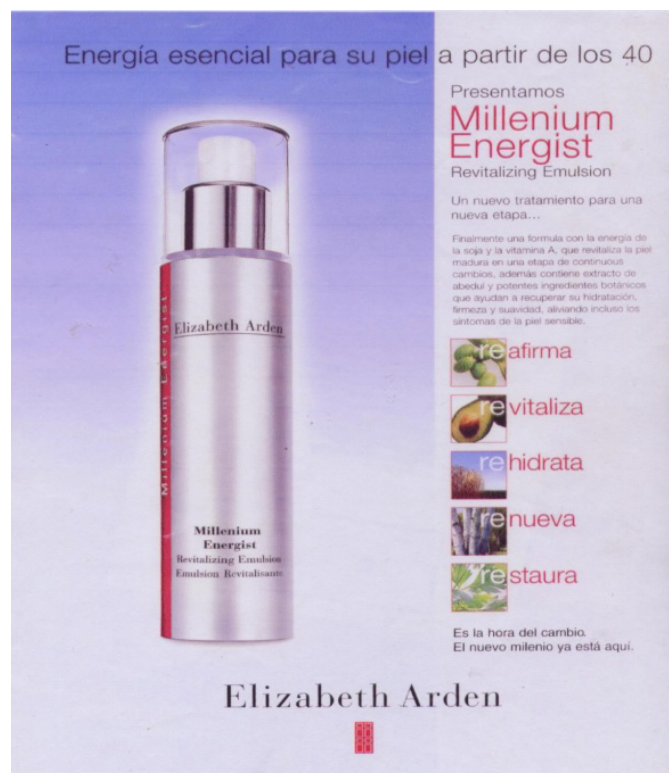

Fig. 3

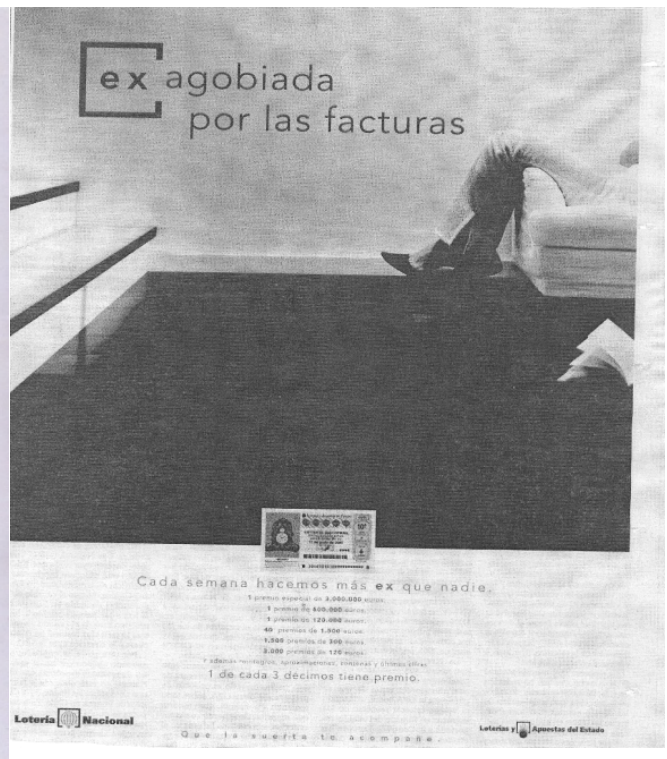

En la figura 3, el marco figurativo, la ubicación textual del prefijo y su separación respecto a la unidad léxica, le conceden relevancia perceptiva hasta convertirlo en foco del que surge el itinerario argumentativo que, a su vez, converge en la sustantivación sobre la que se construye el enunciado posterior: «Cada semana hacemos más ex que nadie».

El valor descriptivo del término «probiótico», en la figura 4, su connotación científica, que lo aproxima a las plastic words, que serán tratadas en el apartado siguiente, quedan resaltados por su distribución en la composición general de la escena, produciendo un efecto contextual dirigido hacia el mensaje que culmina la argumentación: «cucharadas de vida».

Finalmente, hay que hablar de la semantización de la forma gráfica del prefijo, la valoración perceptiva de su efecto tipográfico como principio organizador del espacio visual-comunicativo. La argumentación se focaliza en los rasgos del signo visual dimensión (medida, color, textura), posición y orientación-, sobre el que se construye 
el itinerario de recepción-interpretación del texto. Se trata, en definitiva, de un principio organizador de la escena textual a partir de las cualidades icónicas del prefijo.

Fig. 4

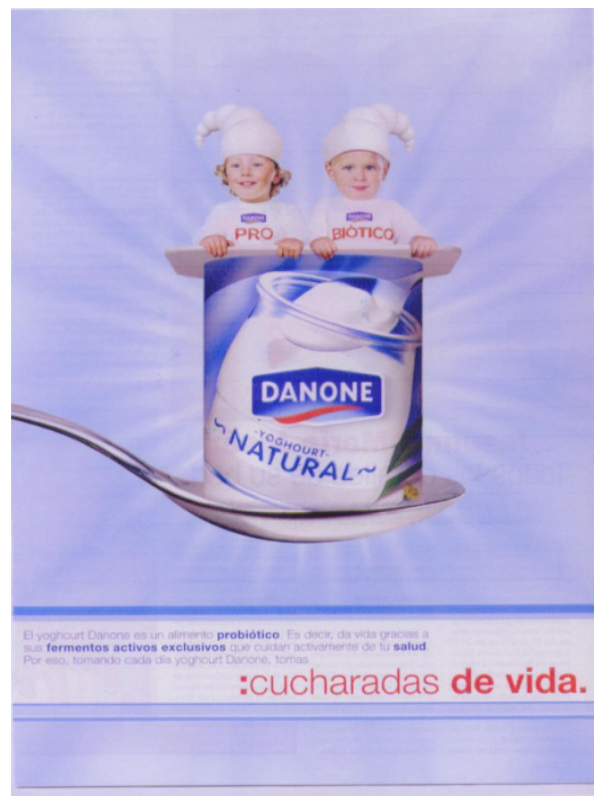

Fig. 5

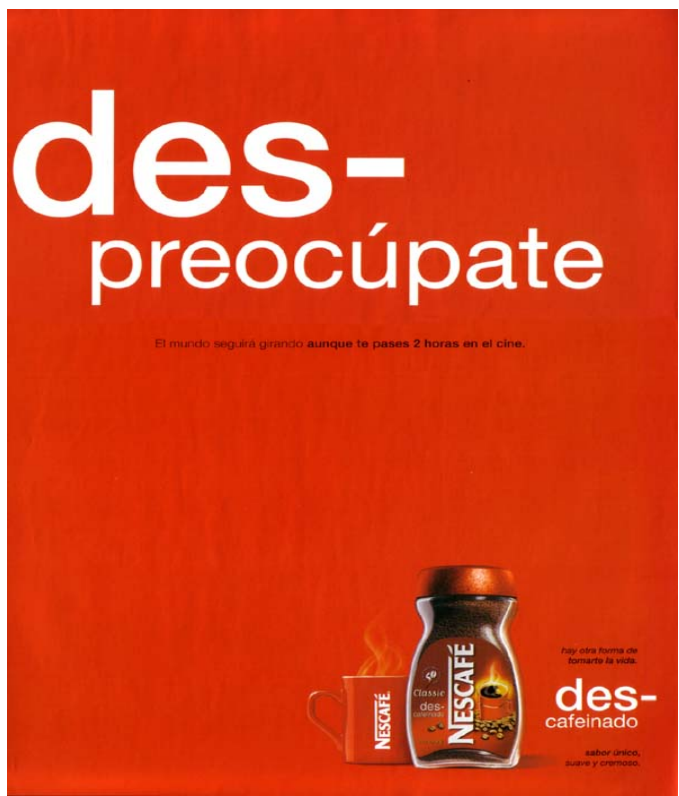

La organización de la textualidad se articula en torno a una red morfofonológica y visual que parte de la marca para proyectarse sobre el eje del foco verbal, constituido por la forma del prefijo argumentativo. Tal es el caso de la figura 5, en la que el escenario discursivo se completa con el siguiente itinerario: des-preocúpate/descafeinado/Nes-café. El recorrido de lectura establece una hilazón, no lineal, entre el argumento hedonista, de salud, la descripción de producto (incidiendo metonímicamente en su condición de café sin cafeína) y, finalmente, el referente de prestigio de la marca.

Más interesantes son los anuncios de las figuras 6 y 7, ambas del grupo Re_acciona. La identidad corporativa del prefijo que ocupa el espacio perceptivo privilegiado se transmite al núcleo del eslogan. En el primer caso, con la reproducción mimética del fomato original a través de la prevalencia del prefijo sobre el resto de la unidad léxica («Re_mediar»). En el segundo, la imagen exclusiva del afijo en la ubicación central del texto constituye un signo inicialmente icónico que, con posterioridad, plantea su función argumentativa al contener un conjunto de vocablos, uniformados por el uso del prefijo, que representan los valores del grupo: reilusionar, reutilizar, reinventar, reorganizar, reconstruir, reeducar, etc. 
Fig. 6

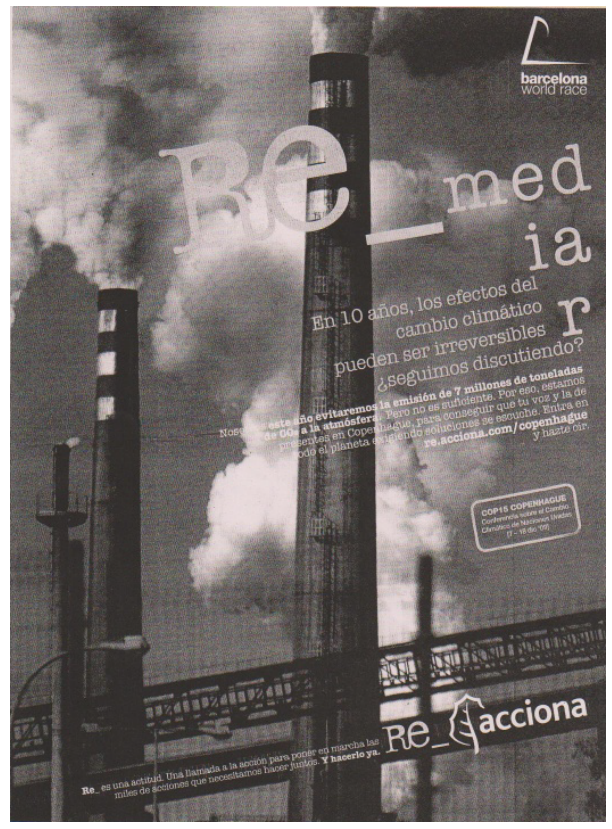

Fig. 7

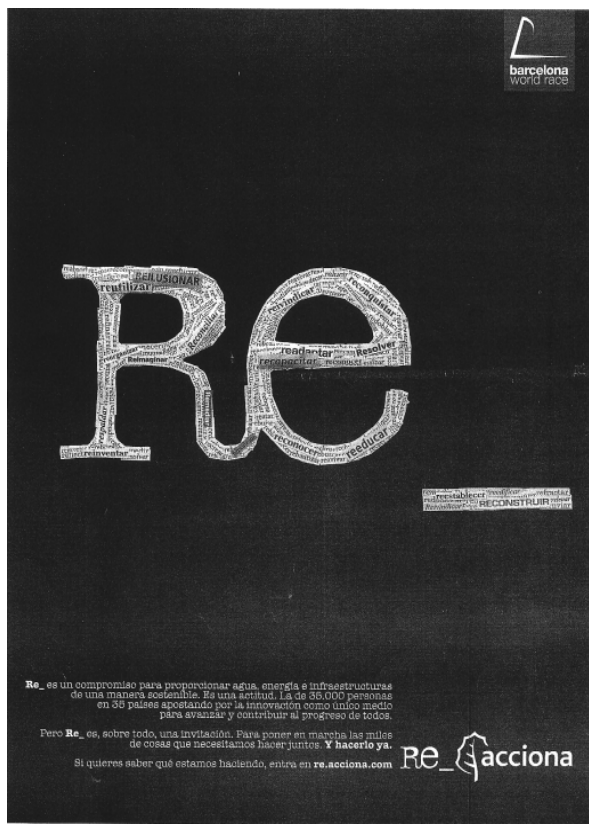

\section{La derivación como mecanismo argumentativo}

La semántica cognitiva ha centrado su interés, durante los últimos años, en el comportamiento de los componentes formales de la palabra, tanto desde el punto de vista de la aportación significativa de los afijos al conjunto de la unidad léxica como de las implicaciones sintácticas de la derivación.

Entre los aspectos más reseñables para la presente investigación, destaca la idea de que, como defiende Felíu ${ }^{10}$, en las palabras prefijadas la estructura léxicoconceptual viene dada por «la palabra base», mientras que el valor semántico del prefijo «funciona como modificador de esa estructura léxico-semántica». En esta línea, Müller ${ }^{11}$, establece que la derivación por prefijos orienta la interpretación del concepto léxico primario, hasta el punto de crear «miniescenarios o marcas preestablecidas de papeles temáticos»».

A partir de estas constataciones, se comprende la estrategia publicitaria dirigida a dotar de prioridad semántico-argumentativa a ciertos prefijos, de uso frecuente dado su potencial connotativo, que será tratado en el apartado siguiente, puesto que no sólo

10 Felíu, E. (2002): «La opacidad sintáctica de las palabras derivadas: una nueva perspectiva», Estudios de Lingüística, 16, 5-46, 36-37.

11 MÜLLER, H. H. (2002): «Principios cognitivos de la formación de palabras en español», en VeIGAS, A.; M. GonZÁLEZ; M. Souto (ed.), Léxico y gramática, Lugo, Tris Tram, 249-259, 254. 
canalizan el proyecto de persuasión verbal, sino que determinan el significado de las bases léxicas y condicionan el sentido del mensaje lingüístico al incidir en las siguientes características:

a.- La manifiesta recurrencia en el uso de formas prefijadas en los anuncios de ciertos productos -especialmente los relacionados con la cosmética y la belleza- revela el interés por incidir en la expresividad de la afijación. Así, por una parte, la acumulación significativa en un texto («reafirmante, redibuja, reafirma, redefine, reduce»-Upgrade de Sensilis-; «regenerador, regenerada -tres veces-, regeneración, rejuvenecida»-One Essential, Dior), y, por otra, su explícita condición compositiva que la muestra como forma neológica, la convierten en un mecanismo argumental que actúa como síntoma del discurso publicitario: la glorificación de lo innovador, de lo efímero, de la inmediatez; en palabras de Braudillard ${ }^{12}$, «gigantescos espacios de circulación, de ventilación, de conexión efímera».

La imagen formal de los vocablos, identificados por la presencia obsesiva del prefijo, expresa el carácter novedoso de la motivación creativa que, a su vez, apunta al impacto innovador del producto pues, como señala García ${ }^{13}$, la publicidad «explota la búsqueda de objetos nuevos», y una vez se han satisfecho las necesidades, el siguiente paso es crear otras necesidades vinculadas con los valores asociados a los objetos.

b.- Hay en todo ello un fonosimbolismo centrado en la virtualidad evocativa del prefijo sobre el que se focaliza el eje argumentativo, función similar a la que Romero Gualda ${ }^{14}$ atribuye al neologismo en el lenguaje político.

Así, el producto Absolue de Lancôme aparece con el siguiente enunciado: «Absolue reconstrucción: renutre, refuerza, revitaliza». La omnipresencia del prefijo re-, que continúa en el resto de la exposición, además de constituir un mecanismo semántico clave en la argumentación, delimita un modelo de actuación lingüística centrado en los valores eufónicos, en las impresiones acústicas y en los efectos connotativos derivados de la presencia continuada del prefijo.

c.- El uso de la prefijación en textos expositivo-informativos tan delimitados en su extensión como los publicitarios tiene, también, una función de economía expresiva. De este modo, el valor aspectual de los prefijos permite evitar fórmulas explicativas más amplias y sin tanta eficacia argumentativa.

Tal es el caso, muy habitual, por otra parte, de la enumeración verbal asociada a la descripción de las cualidades de un producto: «Rehidrata, descongestiona y alisa el contorno del ojo» (Thermal Yeux de Vichy). O, incluso, el de términos cuya derivación

12 BRAUDILlARD, J. (1988): Lo otro por sí mismo, Barcelona, Anagrama, 33-34.

13 GARCíA, C. (2009): «Publicidad y vida cotidiana. La participación de la publicidad en la coformación de la vida cotidiana», Pensar la Publicidad, III, 2, 179-196, 193.

14 Romero Gualda, Ma V. (1995): «Creatividad léxica en el lenguaje político (prefijación)», Rilce, $11-2,263-282,268$. 
resulta forzada, pero resulta ilustrativa de la condensación informativa del procedimiento léxico habilitado: «reproporcionador» (Neovadiol de Vichy), «anti-reaparición» (Dercos de Vichy), «redensificador» (Inneov).

d.- Las tres características anteriores confluyen en el rasgo que mejor define el vocabulario con preternsiones cientifistas de este tipo de productos, tal como recuerda Santiago Guervós ${ }^{15}$ : «neologismos y tecnicismos que aportan autoridad, prestigian los productos y dan cuerpo al mensaje».

La vinculación de numerosos prefijos con el mundo científico, como ya apuntó Lang ${ }^{16}$, su uso en el discurso publicitario con el potencial comunicativo comentado en estas páginas, convierten estos términos derivados en las denominadas plastic words, esto es, vocablos que, en definición de Rodríguez Ponce ${ }^{17}$, adquieren un carácter «litúrgico», como fórmulas ritualizadas que, más allá de su significado denotativo, adquieren su verdadero valor en la capacidad para connotar conceptos relacionados con un universo referencial creado por el propio discurso publicitario.

\section{Prefijación y tópicos publicitarios}

El análisis de la prefijación en el texto publicitario debe dar respuesta a la cuestión clave de todo proceso argumentativo: qué valores, sociales o individuales, proyecta sobre el discurso para que este sea operativo en su finalidad persuasiva. La elaboración del mensaje publicitario ha de ser permeable a los cambios que experimenta la sociedad y a los valores de los distintos grupos de población, pues, como señala Hernán$\mathrm{dez}^{18}$ : «el contexto social internalizado por el individuo está configurando su yo social [...] y ejerce una poderosa influencia en el tipo de repuesta que dé ante la publicidad».

La argumentación publicitaria se nutre de lo que Rey ${ }^{19}$ denomina «depósito, un arsenal, una reserva de lugares comunes» con el objetivo de actuar sobre el «mapa cultural»-variable antecedente del sujeto, en su doble condición, social y personal, según la definición de Bermejo ${ }^{20}$ - para lograr la respuesta favorable del destinatario. En este sentido, los prefijos comentados en estas páginas (re-, anti-, des-), con su incidencia especial en los anuncios dedicados a productos cosméticos y de belleza, aportan

\footnotetext{
15 Santiago, J. (2005): Principios de comunicación persuasiva, Madrid, Arco-Libros, 80.

16 LANG, M. F. (1992): Formación de palabras en español. Morfología derivativa productiva en el léxico moderno, Madrid, Cátedra, 115.

17 Rodríguez, Ma I. (2002): «Los prefijos apreciativos como formantes de plastic words», Anuario de Estudios Filológicos, XXV, 417-432, 420 y ss.

18 HERNÁNDEZ, C. (1998): «Creatividad publicitaria y contexto social», Zer, 4, http://www.ehu.es/zer/

19 REY, J. (2004): «Retórica y consumo. Una propuesta metodológica», Questiones Publicitarias, 1, 9, pp.65-83, 76 .

20 BERMEJO, J. (2008): «Actitud hacia el anuncio y tipología de respuestas publicitarias desde el mapa cultural del receptor», Pensar la Publicidad, II, 1, 93-122, 94-98.
} 
un contenido argumental acorde con la eficacia comunicativa reseñada en los apartados precedentes.

Entre ellos destaca, sin duda, el prefijo re-, con un índice de frecuencia de uso que destaca sobre el resto de morfemas derivativos, $y$ un rendimiento que se aprecia en su uso como signo identificativo de las marcas vinculadas con el mercado del hedonismo y del culto a la imagen. Tal es el caso de Age Re-Perfect de L'Oreal, como aparece en la figura 8 , con un valor connotativo que sitúa el producto entre la gama de cremas cuya función es desarrollar el sentido simbólico del significado lexico del prefijo («volver a ..»), «recuperar..»). El resto de la escena, con sus referentes verbales («Pieles maduras») e icónicos (Jane Fonda), contextualiza el recorrido metafórico del afijo hacia su eficacia persuasiva.

Fig. 8

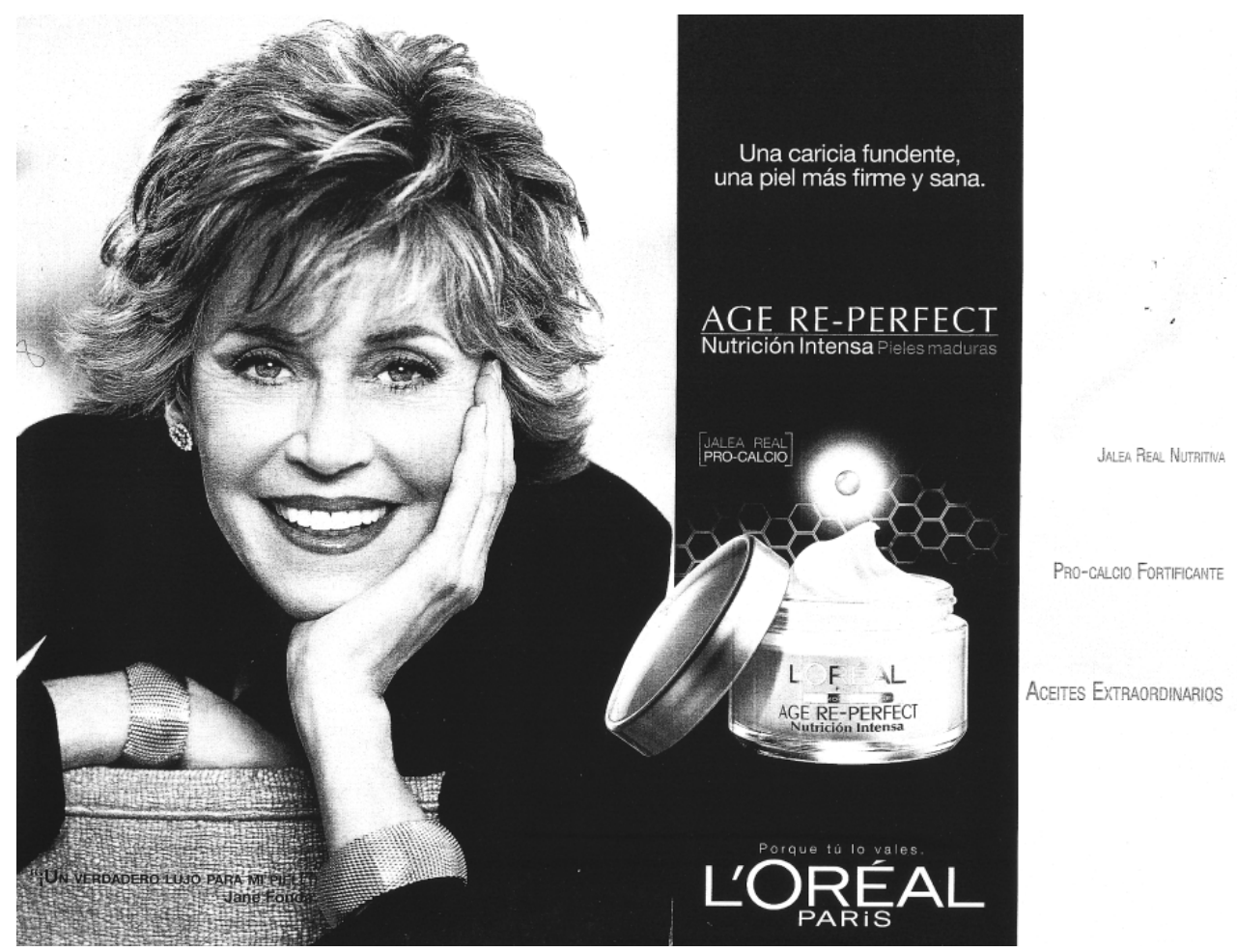

La presencia del citado prefijo en textos dirigidos a publicitar un segmento concreto del mercado - «refuerza, revitaliza, rehidrata, renueva, rejuvenece, reilusionar, reconstruir...»-, su inclusión como eje del proceso argumentativo y foco perceptivo primario, lo convierten en uno de los mecanismos privilegiados del discurso publicitario. Su valor aspectual, marcado por el sentido de la reiteración y de la recuperación, le permite entroncar con uno de los tópicos que sustentan el universo de la publicidad: la 
posibilidad de actuar contra el paso del tiempo, recreando mitemas capaces de articular estrategias que enlazan con obsesiones del imaginario colectivo contemporáneo.

En efecto, la actualizacón del mito de Prometeo -el hombre arrebata el secreto de la vida a los dioses- o el esbozado por la figura de Dorian Grey -la eterna juventud-, por citar dos referentes integrados en el componente antropológico de la cultura, reflejan uno de los rasgos identificativos del pensamiento individualista en las sociedades capitalistas avanzadascomo señala Lukes ${ }^{21}$ : «la autoperfección [...] el grado de perfeccionamiento de la individualidad». En esta líneas, la publicidad insiste en promocionar la figura del individuo y la autoconciencia de su identidad «como artesano principal de la cultura hedonista», en atinada descripción de Lipovetsky ${ }^{22}$.

La prefijación, con el prestigio que le concede su resonancia cientifista, transmite fundamentos temáticos dirigidos a recobrar el control personal de la experiencia vital del individuo, bien a través de referencias a recursos que contribuyen a superar la contingencia temporal (re-, pro-), a los que multiplican sus efectos intensivos y cuantitativos (prefijos superlativos, ultra-, super-, mega-), y a los que, por su carácter opositivo, garantizan la lucha contra la decadencia física (anti-, contra-, des-).

Se cumple así uno de los planteamientos primigenios de la publicidad, basado en la transmisión de una confianza en las aportaciones del mercado a la construcción de la imagen identitaria catalizadora del universo personal, desde una óptica euforizante centrada en las posibilidades de realización individual a través de la confianza en el avance tecnológico y científico. De este modo, el consumo se convierte en una «neorreligión, como elemento sustitutivo de lo sacro», como señala Huici ${ }^{23}$, en el que se recrea un universo donde se cumplen las expectativas, se refuerza la autoestima, la seguridad en la capacidad humana sobre la naturaleza, se neutralizan las amenazas externas y se devuelve al hombre el dominio sobre su propio destino.

El discurso en torno al consumo, sustentado sobre la dimensión sacra basada en la sublimación de los ideales comunitarios, se orienta, además, hacia el pragmatismo del saber cotidiano, hacia la experiencia diaria de las personas, con soluciones al alcance de cualquiera como exponentes de un mundo posible que dependen de la voluntad individual y de la confianza en los dogmas del mercado. Como indica Benavides ${ }^{24}$ : «los contenidos publicitarios no remiten a una cultura original, sino a la cultura cotidiana». Los mensajes publicitarios van más allá de la imagen mimética de la realidad para proponer «una ficción verosímil en forma de estrategia de vida» (Conejero, 1995: 149).

21 LuKES, S. (1975): El individualismo, Barcelona, Península, 92.

22 LiPOVETSKY, G. (1986): La era del vacio. Ensayos sobre el individualismo contemporáneo, Barcelona, Anagrama, 84.

23 HuICI, A. (2007): «En busca del sentido perdido. De la religión y la utopía al paraíso del consumo», Questiones Publicitarias, I, 12, pp. 63-76, 72.

24 BENAVIDES, J. (1995): «La presencia de la publicidad en la construcción de la cultura cotidiana», Especulo, 1, http://www.ucm.es/info/especulo/numero1/benavid.htm 


\section{Conclusión}

El uso de la prefijación en los textos publicitarios es un síntoma de los rasgos que definen este tipo de discurso, tanto en lo que afecta al modelo de su estrategia argumentativa como en la respuesta comportamental que pretende suscitar a la hora de convertir al destinatario en consumidor potencial de un producto.

Su elección como mecanismo persuasivo obedece a los diferentes factores que intervienen en la textualización del proceso discursivo:

- En primer lugar, la fijación de un foco perceptivo sobre el que se genera la organizazación del mensaje, tomando en consideración tanto la dimensión perceptiva de los elementos como el anclaje entre códigos -icónico y verbal- que vertebran el itinerario de lectura no lineal del texto publicitario.

- A continuación, como eje de la argumentación, articula un principio de coherencia temática que se disemina por los diferentes niveles de la estructura textual, garantizando así la preeminencia del valor aspectual del afijo.

- Finalmente, afecta a la esfera cognitiva del destinatario al incidir en constantes del imaginario colectivo, proponiendo alternativas cotidianas a las limitaciones de la experiencia vital del individuo.

La prefijación muestra, así, su operatividad en las diferentes fases que constituyen la singularidad perceptiva del texto publicitario: la fisiológica (la que determina la «línea de indicatibilidad», en palabras de Gubern ${ }^{25}$ ); la cognitiva, al proponer un modelo argumentativo que interactúa con el repertorio del receptor (conjunto de conocimientos integrados en la competencia del destinatario); y la mnemotécnica, al actuar sobre el dominio de las creencias, valores personales y sociales del consumidor, en forma de macroproposiciones cimentadas sobre tópicos culturales.

\section{Referencias bibliográficas}

ADAM, J. y M. BONHOMME (2000): La argumentación publicitaria. Retórica del elogio y de la persuasión, Madrid, Cátedra.

BENAVIDES, J. (1995): «La presencia de la publicidad en la construcción de la cultura cotidiana», Especulo, 1, http://www.ucm.es/info/especulo/numero1/benavid.htm Web visitada el $3 / 2 / 2011$.

BERMEJO, J. (2008): «Actitud hacia el anuncio y tipología de respuestas publicitarias desde el mapa cultural del receptor», Pensar la Publicidad, II, 1, 93-122.

BRAUDILlARD, J. (1988): Lo otro por sí mismo, Barcelona, Anagrama.

CodelupPI, V. (2007): «El papel social de la publicidad», Pensar la Publicidad, I, 1, 144-155.

CONEJERO, M. (1995): «Lenguaje publicitario hoy: del pedazo de vida a la estrategia de vida», en Bermúdez, J; M. FARRelL; LL. Meseguer (eds.), Subjecte i creativitat, Castellón, Universitat Jaume I, 149-156.

GUBERN, R. (1979): El lenguaje de los cómics, Barcelona, Península, 54. 
FELÍU, E. (2002): «La opacidad sintáctica de las palabras derivadas: una nueva perspectiva», Estudios de Lingüistica, 16, 5-46.

GARCÍA, C. (2009): «Publicidad y vida cotidiana. La participación de la publicidad en la coformación de la vida cotidiana», Pensar la Publicidad, III, 2, 179-196.

GuBERN, R. (1979): El lenguaje de los cómics, Barcelona, Península.

Guerrero, S. (2007): La creatividad en el lenguaje perodístico, Madrid, Cátedra.

GUTIÉRREZ ORDÓÑEZ, S. (2000): Temas, remas, focos, tópicos y comentarios, Madrid, ArcoLibros.

HERNÁNDEZ, C. (1998): «Creatividad publicitaria y contexto social», Zer, 4, http://www.ehu.es/zer/ .Web visitada el 2/2/2011.

Huici, A. (2007): «En busca del sentido perdido. De la religión y la utopía al paraíso del consumo», Questiones Publicitarias, I, 12, 63-76.

KRÜGER, R. (1990): «L'écriture et le conquête de l'espace plastique: comment le texte es devenu image», en MonTANDON, A. (ed.), Signe/texte/image, Lyon, Césura Lyon Edition, 13-61.

LANG, M. F. (1992): Formación de palabras en español. Morfología derivativa productiva en el léxico moderno, Madrid, Cátedra.

LIPOVETSKY, G. (1986): La era del vacio. Ensayos sobre el individualismo contemporáneo, Barcelona, Anagrama.

LOMAS, C. (1996): El espectáculo del deseo. Usos y formas de la persuasión publicitaria, Barcelona, Octaedro.

LUKES, S. (1975): El individualismo, Barcelona, Península.

MÜlleR, H. H. (2002): «Principios cognitivos de la formación de palabras en español», en VEIGAS, A.; M. GonZÁLEZ; M. SouTo (ed.), Léxico y gramática, Lugo, Tris Tram, 249259.

REY, J. (2004): «Retórica y consumo. Una propuesta metodológica», en Questiones Publicitarias, $1,9,65-83$.

RoBles, S. (2004): Realce y apelación en el lenguaje de la publicidad, Madrid, Arco-Libros.

RODRÍGUEZ, M I I. (2002): «Los prefijos apreciativos como formantes de plastic words», Anuario de Estudios Filológicos, XXV, 417-432.

Romero GuALDA, Ma V. (1995): «Creatividad léxica en el lenguaje político (prefijación)», Rilce, 11-2, 263-282.

- (2005): «Texto e imagen en el texto publicitario», en ROMERO

GuALDA, MaV. (coord.), Lenguaje publicitario, Barcelona, Ariel, 83-87.

SANTIAGO, J. (2005): Principios de comunicación persuasiva, Madrid, Arco-Libros.

Recibido: 11 de abril de 2011

Aceptado: 18 de septiembre 2011 